\title{
Gender-Related Traits as Predictors of Alcohol Use in Male German and Spanish University Students
}

\author{
Friederike Zimmermann • Monika Sieverding • \\ Stephanie M. Müller
}

Published online: 23 November 2010

(C) Springer Science+Business Media, LLC 2010

\begin{abstract}
This study examined instrumental (masculine stereotyped) and expressive (feminine stereotyped) personality traits and alcohol use among men from Germany and Spain. Participants were 161 male university students (76 German, $M_{\text {age }}=23$ years; 77 Spanish, $M_{\text {age }}=22$ years), who completed either a daytime or a nighttime drinking questionnaire, each including a Short Form of the Bem Sex Role Inventory. Poisson regression analyses with latent predictors were conducted. The trait factors and their interactions with nationality predicted daytime and nighttime alcohol use. The results add support to the assumption that alcohol use is associated with the construction of masculinity and that internalization of traditionally female attributes protects against health-risk behaviors such as alcohol consumption.
\end{abstract}

Keywords Gender role · Masculine attributes · Feminine attributes $\cdot$ Alcohol $\cdot$ Cross-national research

\section{Introduction}

Adverse consequences of alcohol consumption are considerable and have been consistently found to be more prevalent among men than women (Perkins 2002; Wilsnack et al. 2000). Accordingly, gender differences in drinking

F. Zimmermann $(\square) \cdot$ M. Sieverding

Department of Psychology, University of Heidelberg,

Hauptstraße 47-51,

69117 Heidelberg, Germany

e-mail: friederike.zimmermann@psychologie.uni-heidelberg.de

S. M. Müller

Department of Experimental Psychology, University of Granada, 18071 Granada, Spain behavior have been found throughout countries all over the world, with men drinking larger amounts, more frequently, and more often heavily than women on average (Mäkelä et al. 2006; Wilsnack et al. 2009). The description of gender differences, however, ignores the substantial within-group variability in men and women. Because not all men engage equally in unhealthy behaviors such as heightened alcohol use, the question is why some men do more so than others. The present article addresses this question by investigating individual differences in gender-stereotyped instrumental and expressive traits representing masculine and feminine gender-role influences that may account for the variance in men's alcohol use. The impact of culture on gender roles, drinking habits, and their relationship has only recently been acknowledged. In this vein, variations across cultures are to be expected. Nevertheless, the gender-alcohol link may be relevant for many countries since substantial gender differences in alcohol use have been observed worldwide (Wilsnack et al. 2009). Research has been conducted on masculinity (but rarely on femininity) and alcohol use in some countries (e.g., Mahalik et al. 2006; Van Gundy et al. 2005), but mostly in the US (e.g., Huselid and Cooper 1992; Landrine et al. 1988; Snell et al. 1987). This study, for the first time, addresses gender and alcohol use in German and Spanish men; thereby, the gender-related trait measures were assessed with questionnaires in a crosssectional field study and were ensured to be comparable across the two countries by measurement invariance testing.

Gender-role variables may explain between- and withingender differences in alcohol use (Nolen-Hoeksema and Hilt 2006; Waldron 1988). In this sense, individuals may differ from one another in their use of alcohol depending on the extent to which they are attuned to the cultural definitions of masculinity and femininity. To enact masculinity and to increase the likelihood that masculine 
attributes (rather than feminine) are incorporated into the self, men must generally adhere to the culturally defined masculine behaviors (and reject what is feminine; cf. Eagly et al. 2000; Hannover 2000). The social practices that undermine health (Courtenay 2000a), for example, such as alcohol consumption (Lemle and Mishkind 1989) are assumed to serve as indicators of masculinity. Recent qualitative research supports this view by showing that alcohol use is linked to attributes of the male role such as risk taking, dominance, strength, and invincibility (Peralta 2007). Although there are multiple discourses of being "masculine," the hegemonic notion of masculinity in Western societies relates to this traditionally masculine ideal.

To date, quantitative studies on gender roles have applied diverse measures covering different aspects of masculinity and femininity, since these are conceived to be multifaceted constructs (Deaux and LaFrance 1998). Scholars using the Conformity to Masculine Norms Inventory (Mahalik et al. 2003) found moderate evidence for the positive and negative relations of masculinity to men's health-risk behaviors and health-protective behaviors in samples from Australia (Brown and Bond 2008; Mahalik et al. 2007b) and from the US (Mahalik et al. 2007a). Among male college students drawn from the US and Kenya, alcohol use was positively associated with conformity to masculine norms (Mahalik et al. 2006). A study involving US undergraduates found that masculine attributes were positively correlated with the items "drinking beer" and "getting drunk," and were more often assigned to male stimuli (e.g., "a really macho man") than to female stimuli (Landrine et al. 1988). Other gender-role measures that were used included, for example, self-descriptions with instrumental/agentic (traditionally masculine) and expressive/communal (traditionally feminine) personality traits (as assessed by the Bem Sex Role Inventory [BSRI], Bem 1974, 1981; or by the personal attributes questionnaire [PAQ], Spence and Helmreich 1978). For example, the endorsement of extreme or socially undesirable personal attributes - such as in unmitigated agency assessed with the extended PAQ - was positively associated with alcohol use and other forms of substance use among undergraduates from the US (Danoff-Burg et al. 2006; Snell et al. 1987). McCreary et al. (1999) found that, among the three male role variables used, traditional attitudes predicted alcohol consumption among Canadian men; however, neither masculine gender-role stress nor agentic traits (assessed with the PAQ) were predictive of alcohol use. Huselid and Cooper (1992) also followed a multiple measures approach. Their results showed that, whereas instrumentality (assessed with the PAQ) was not correlated with measures of alcohol use, traditional gender-role attitudes were associated with more frequent alcohol use and intoxication in adolescents from the US. Thus, studies using multiple gender-role measures yielded moderate support for the alcohol-masculinity hypothesis on single measures.

There is a lack of research on feminine qualities and health-related behaviors in men. Researchers have argued that it is high expressiveness/communion in androgynous people (who are also high in instrumentality/agency) that renders them more resistant to social pressure to engage in health-risk behaviors (Evans et al. 1990; Shifren et al. 1993). Findings from a 17 -year longitudinal study by Hunt et al. (2007) indicated a protective effect of feminine attributes. In their sample of middle-aged Scottish men and women, mortality from coronary heart disease was lower for men who were high in expressiveness (assessed with the Short Form BSRI). Hunt and colleagues (2007) did not investigate mediating variables. However, less alcohol consumption may be a candidate for explaining the protective effects of expressiveness on health. To date, the very few existing studies, which have been conducted in the US, have shown a relation between expressiveness and less frequent alcohol use in adolescents (Huselid and Cooper 1992) and less alcohol use in young women-but not in men (Snell et al. 1987).

As can be seen from the review of the literature, a growing amount of evidence has suggested a relation between gender roles and alcohol use. However, little quantitative research has been done outside the United States on this topic. It has been recommended to consider a broader cultural context when investigating gender issues (Deaux and LaFrance 1998) since societies may vary in the degree to which they endorse traditional gender norms (e.g., Tager and Good 2005) and in their construction of gendered health-behavior norms (Courtenay 2000b). As empirical findings have shown, the consideration of culture may even lead to the detection of unexpected results. Van Gundy et al. (2005) found that instrumentality (assessed with the BSRI) was related to less alcohol consumption in men from Russia, and expressiveness (assessed with the PAQ) was related to more alcohol consumption in women from Canada. The authors interpreted their findings in terms of the cultural backgrounds of the people studied and contended the necessity to be careful in generalizing results that are mainly based on US samples.

\section{The Present Investigation}

The aim of the present study was to extend previous research on gender-related attributes and alcohol use. We investigated this topic in Germany and Spain, two countries with quite different distributions of social roles between men and women. The higher gender inequality in Spain is reflected by women participating less in economic and 
political activities than in Germany (Lopez-Claros and Zahidi 2005; United Nations Development Programme 2003). This is also underlined by gender differences in domestic tasks, which are still female dominated in both countries; however, Spanish men spend even less time (1 hr $37 \mathrm{~min}$ ) working in the household each day than German men (2 hr 21 min; see Eurostat 2006).

Differences in cultural drinking norms and habits have also been observed (Room and Mäkelä 2000). These may depend in part on legal codes related to drinking, which differ between countries. In Germany, it is legal to buy and drink spirits and drinks containing spirits from the age of 18; adolescents are allowed to buy and drink beer and wine from the age of 16, and are allowed to drink these types of alcohol under 16 years of age when under parental supervision (Bundesministerium der Justiz 2008). In Spain, it is legal to buy and drink alcoholic beverages of all types from the age of 16, but some of the autonomous communities have increased the legal drinking age to 18 within the last decade (Ministerio de Sanidad y Consumo 2008). Frequent alcohol use such as daily light or moderate drinking is much more integrated into everyday life in Mediterranean countries, particularly in Spain (Hupkens et al. 1993) as opposed to other European countries (Bloomfield et al. 2003; Leifman 2002). In Spain, it appears to be common to consume some alcohol during the day (e.g., at any mealtime), whereas in Germany it seems to be common to start drinking after work (e.g., to have some "FeierabendBier" during knocking-off time). It is less clear, however, whether such heavier alcohol use (e.g., binge drinking), which commonly takes place in the evenings, is still more frequent among adults from the northern parts than from the southern parts of Europe (Bloomfield et al. 2003; Kuntsche et al. 2004). We covered two time conditions to get a more complete picture since the social pressure to drink alcohol may be different for German and Spanish men during the daytime or in the evenings.

Although most of the literature relating alcohol to masculinity originates from scholars from the US, there is reason to assume that the alcohol-masculinity link applies to Germany and Spain as well. It has been observed that the objects most often exchanged among Spanish men were cigarettes and glasses of sherry, wines, liquors, and beer, and that any other behavior would have been perceived as deviant (Gilmore 1990a). The public and ritualized exchange and use of alcoholic drinks among Spanish men, thus, seems to be linked to manhood. Gender-typed risk behavior, such as the excessive use of alcohol among German boys, has been noted to serve the function of constructing a gendered self from adolescence on (Helfferich 1997). This linkage between substance use and masculine identity is increasingly acknowledged in Germany, and a call for implementing gender in prevention and rehabilitation efforts addressed at men's drug use has been expressed (Stöver 2007).

Some of the studies reviewed investigated the combination of high or low scores in both of the gender-stereotyped trait scales. It has been found, for example, that "androgyny" (high instrumentality and high expressiveness) was related to better health-related behaviors, such as less smoking - in contrast to the other combinations "masculinity," "femininity," and "undifferentiated" (Evans et al. 1990; Shifren et al. 1993). To classify people into these four groups, based on the combination of their (high or low) mean scores on the two scales, Bem suggested that the median-split on instrumentality and expressiveness should be used (Bem 1977). However, many researchers have questioned the use of the median-split approach (MacCallum et al. 2002), for instance, to form the four distinct types by dichotomization of the gender-related trait scales (cf. Hoffman and Borders 2001). To consider possible subgroups of combinations in the two trait factors-while making full use of the continuous measures-we included the product term of instrumentality and expressiveness next to their main effects in our study (cf. Cohen et al. 2003).

The aim of the present research was to investigate predictors of daytime and nighttime alcohol use; the specific hypotheses were as follows:

1. Daytime alcohol use (a) will be more frequent among Spanish men than among German men, (b) will be more frequent with higher scores on instrumentality, (c) will be less frequent with higher scores on expressiveness, (d) will be predicted by the interaction of instrumentality and expressiveness; (e) predictions $2 b$, $2 \mathrm{c}$ and $2 \mathrm{~d}$ will be moderated in strength by nationality.

2. Nighttime alcohol use (a) will be related to nationality, (b) will be more frequent with higher scores on instrumentality (c) will be less frequent with higher scores on expressiveness, (d) will be predicted by the interaction of instrumentality and expressiveness; (e) predictions $3 \mathrm{~b}, 3 \mathrm{c}$ and $3 \mathrm{~d}$ will be moderated in strength by nationality.

\section{Method}

Samples and Procedure

Participants were 153 men, 76 German $\left(M_{\text {age }}=23.4, S D=\right.$ 2.7 years; Range $=19-29)$ and 77 Spanish $\left(M_{\mathrm{age}}=22.0\right.$, $S D=2.7$ years; Range $=19-29)$. Both samples were recruited at university campuses (in Heidelberg, Germany and Granada, Spain). All participants attended their universities in diverse domains; the most frequent majors were psychology (36\%), economics (18\%), and languages 
$(15 \%)$ in the Spanish sample, and physics (14\%), history $(11 \%)$, and economics, law, and political science (each $10 \%$ ) in the German sample. Participants were randomly assigned to complete a daytime or a nighttime drinking questionnaire. Anonymity was assured and no identifying personal information was requested.

\section{Measures}

The questionnaires of daytime and nighttime alcohol use assessed actor and abstainer prototype perception, social norms, gender-stereotyped personality traits, and basic socio-demographic data. Results regarding prototypes and norms are not reported in this article.

Gender-stereotyped traits were measured using an adaptation of the Short Form of the Bem Sex Role Inventory (BSRI; Bem 1981). The M and F scales of the Short Form assess an individual's self-description with positively valued instrumental and expressive attributes. That is, the $\mathrm{M}$ scale focuses on characteristics that are targeted at personal goal-attainment, and the F scale focuses on characteristics that are associated with the consideration of others and their welfare (cf. Bem 1974). The allocation of items into either the $\mathrm{M}$ or the $\mathrm{F}$ scale was based on cultural stereotypes about men and women rather than on gender differences in these items (Bem 1974). Hence, the BSRI assesses individual differences in attributes that have been consistently judged to be significantly more desirable (in American society) for a man than for a woman (instrumental attributes) or for a woman than for a man (expressive attributes). People's endorsement of the attrib- utes is rated on a scale from 1 (never or almost never true) to 7 (always or almost always true). An individual's extent of instrumentality and expressiveness is represented by the mean of corresponding items with higher scores indicating a greater degree of instrumentality or expressiveness, respectively. The two scales are conceptually and empirically independent from each other (Bem 1974).

The BSRI Short Form (Bem 1981; see also Hunt et al. 2007) was translated into German based on the German version of the BSRI (Schneider-Düker and Kohler 1988) and on a qualitative review of the meaning of items. Four items were eliminated based on their translated content (e.g., "aggressive" is not socially desirable in German, but has a negative connotation). The items were translated into Spanish based on a Spanish version of the BSRI (GarciaRetamero and Lopez-Zafra 2006). A back-translation of the whole questionnaire into German through a different bilingual person, who was blind to the German version, provided qualitative support for the comparability of items. Reliability according to Cronbach's alpha was sufficient to high for instrumentality $\left(\alpha_{\text {overall }}=.76\right.$; $\left.\alpha_{\text {Germany }}=.82 ; \alpha_{\text {Spain }}=.70\right)$ and for expressiveness $\left(\alpha_{\text {overall }}=.84 ; \alpha_{\text {Germany }}=.89 ; \alpha_{\text {Spain }}=.73\right)$. The dimensions were not correlated $\left(r_{\text {overall }}=.12, p=.15 ; r_{\text {Germany }}=.19\right.$, $\left.p=.10 ; r_{\text {Spain }}=.03, p=.82\right)$, as was expected since they are conceptualized as orthogonal dimensions (Bem 1974). See Table 1 for the English items of the Short Form of the BSRI used in this study along with the German and Spanish translations. To establish a well-fitting measurement model, we revised the scales according to item and scale properties. Consequently, five items each assessed instrumentality

Table 1 English items of the short form of the BSRI used in this study along with the German and Spanish translations

\begin{tabular}{|c|c|c|c|}
\hline & English & German & Spanish \\
\hline \multirow[t]{8}{*}{ Instrumentality } & Defend my opinion & Verteidige eigene Meinung & Defiendo mi opinión \\
\hline & Independent & Unabhängig & Independiente \\
\hline & Assertive & Durchsetzungsfähig $^{\mathrm{a}}$ & Convincente $^{\mathrm{a}}$ \\
\hline & Strong personality & Starke Persönlichkeit ${ }^{\mathrm{a}}$ & Tengo carácter/personalidad fuerte ${ }^{a}$ \\
\hline & Forceful & Kraftvoll $^{\mathrm{a}}$ & Enérgico $^{\mathrm{a}}$ \\
\hline & Have leadership abilities & Habe Führungsqualitäten ${ }^{\mathrm{a}}$ & Capacidad de liderazgo $^{\mathrm{a}}$ \\
\hline & Willingness to take risks & Bereit, etwas zu riskieren ${ }^{a}$ & Audaz ${ }^{\mathrm{a}}$ \\
\hline & Dominant & Dominant & Dominante \\
\hline \multirow[t]{8}{*}{ Expressiveness } & Affectionate & Herzlich & Afectuoso \\
\hline & Sensitive to the needs of others & Sensibel für die Bedürfnisse anderer ${ }^{\mathrm{a}}$ & Sensible a las necesidades de los otros ${ }^{\mathrm{a}}$ \\
\hline & Tender & Zart $^{\mathrm{a}}$ & Delicado $^{\mathrm{a}}$ \\
\hline & Warm-hearted & Warmherzig & Cálido \\
\hline & Eager to soothe hurt feelings & Bemüht, verletzte Gefühle zu besänftigen ${ }^{\mathrm{a}}$ & Capacidad para ponerme en el lugar del otro ${ }^{\mathrm{a}}$ \\
\hline & Gentle & Sanft & Suave \\
\hline & Understanding & Verständnisvoll $^{\mathrm{a}}$ & Comprensivo $^{\mathrm{a}}$ \\
\hline & Compassionate & Mitfühlend $^{\mathrm{a}}$ & Compasivo $^{\mathrm{a}}$ \\
\hline
\end{tabular}

${ }^{a}$ Item used as indicator of the latent trait factor instrumentality or expressiveness, respectively. 
("assertive," "strong personality," "forceful," "have leadership abilities," and "willingness to take risks"; Cronbach's $\alpha_{\text {overall }}=.73 ; \alpha_{\text {Germany }}=.78 ; \alpha_{\text {Spain }}=.68$ ) and expressiveness ("sensitive to the needs of others," "tender," "eager to soothe hurt feelings," "understanding," and "compassionate"; Cronbach's $\alpha_{\text {overall }}=.78 ; \alpha_{\text {Germany }}=.82 ; \alpha_{\text {Spain }}=.70$ ).

The outcome variables referred to self-reported frequencies of alcohol use and varied between subjects. In one condition, the number of days in which alcohol was consumed (daytime alcohol use) within a typical week was requested; in the other condition, this related to the number of evenings in which several glasses of alcohol were consumed (nighttime alcohol use). In each case, participants indicated the number of days within a typical week using an open format. In the daytime condition, any alcohol consumption during daytime (i.e., before 6.00 p.m.) was of interest. In the nighttime condition, consumption of several glasses of alcohol during the evening was defined as drinking more than three alcoholic drinks in Germany, and-because of generally smaller public drink sizesmore than four alcoholic drinks in Spain. For example, a regular glass of beer contains $330 \mathrm{ml}$ and a glass of wine typically contains $200 \mathrm{ml}$ in Germany, whereas in Spain, a glass of beer contains $250 \mathrm{ml}$ and a glass of wine $120 \mathrm{ml}$ (Rodríguez-Martos Dauer et al. 1999). Formerly, in southern European countries such as Spain, wine consumption was more common than beer consumption and vice versa in northern European countries such as Germany; nevertheless, these differences are disappearing since the European countries seem to converge with regard to beverage choices (Hupkens et al. 1993). We are aware of the fact that our measure at best constitutes a lower limit of what is generally qualified as "binge drinking"; numerous problems are associated with its definition amongst which varying public drink sizes across countries is only one aspect (Gmel et al. 2003). Nevertheless, the quantities of several alcoholic drinks used clearly exceed tolerable amounts of daily alcohol intake (British Medical Association 1995; Robert Koch-Institut 2003) and have been associated with increased risk of several cancers and other severe diseases (Corrao et al. 2004).

\section{Data Analyses}

A preliminary confirmatory factor analysis was conducted to specify a two-dimensional model of the genderstereotyped traits as latent constructs adjusted for measurement error, which were used as predictors in the later regression analyses. To establish a well-fitting measurement model, the scales were slightly shortened (see the measures section) according to item and scale properties.

Valid conclusions regarding the role of the gender-related trait factors for alcohol use in our German and Spanish samples require, first of all, adequate cross-national measurement invariance of the scales used (cf. Meredith and Teresi 2006). Thus, the latent trait factors of instrumentality and expressiveness were subjected to a series of multigroup confirmatory factor analyses with ascending restrictiveness (cf. Muthén and Muthén 1998-2007; Steenkamp and Baumgartner 1998). Step by step, the factorial pattern of indicators, factor loadings, item intercepts, and residual variances of the items are constrained to be equal across groups. Following each step, the fit of the restricted model is evaluated relative to the less restrictive model, respectively. If the more restrictive model does not fit significantly worse compared with the less restrictive one, this indicates invariance between the groups on the higher level (Vandenberg and Lance 2000). As recommended in testing of measurement invariance, the nonarbitrary method of identifying latent variables introduced by Little and colleagues (2006; see also Steinmetz et al. 2009) was used.

As a further preliminary analysis, a 2 (nationality) $\times 2$ (time condition) MANOVA, followed by the single ANOVAs, was conducted to test for differences in the study variables (instrumentality, expressiveness, frequency of alcohol use) across countries and for any differences in the gender-related traits across time conditions and countries. When there were significant interactions, subsequent $t$ tests (without assuming equal variances) were computed.

Finally, the gender-stereotyped trait factors were entered as latent predictors in regression analyses with daytime and nighttime alcohol use as the dependent variables. The frequency distributions for these count variables were characterized by poisson distributions (cf. Cohen et al. 2003). That is, they followed discrete probability functions referring to the number of events occurring in a particular period of time (the number of days in which a certain amount of alcohol was used within a typical week); scores were integers and nonnegative (with possible values from 0 to 7). Poisson distributions are often characterized by excesses of low scores, non-normality, and heteroscedasticity of residuals (cf. Cohen et al. 2003). There were indeed many men drinking on only a few days in our data. Thus, both dependent variables were not normally distributed (but significantly positively skewed; critical ratio of skew to its standard deviation was 3.09 for nighttime alcohol use and 3.14 for daytime alcohol use) and exhibited heteroscedasticity (the variance of the residuals depended on the predicted variable itself as was shown by the pattern of spread when plotting the residuals vs. the predicted values). Since assumptions such as normality and homoscedasticity were violated, results may be seriously biased when applying conventional linear methods to such count data (Cohen et al. 2003). Thus, regression analyses were accomplished by using poisson regression. Conventional 
estimates of model fit are not available in poisson regression and only unstandardized path coefficients are available. The poisson regression coefficients can be best interpreted when exponentiated yielding incidence rate ratios (IRR). For a 1-unit increase in the predictor variable, the predicted count increases or decreases as multiplied by IRR (Cohen et al. 2003).

All analyses that were based on the structural equation modeling approach were computed using Mplus (Muthén and Muthén 2008). Less than $1 \%$ of the values were missing for the study variables and were treated with full information maximum likelihood simultaneously with model estimation; for computing descriptive statistics, missing data were estimated using the expectation maximization algorithm in NORM (Schafer 1999), which is an excellent option for this purpose (Graham 2009).

\section{Results}

\section{Preliminary Results}

The measurement model, which consisted of five indicators for each latent gender-stereotyped trait factor, fit the data very well, $\chi^{2}(29)=26.00, p=.63 ; C F I=1.00, T L I=1.00$, $R M S E A=.00, S R M R=.04$. The latent factors were not correlated $\left(r_{\text {overall }}=.15, p=.21 ; r_{\text {Germany }}=.16, p=.36\right.$; $\left.r_{\text {Spain }}=.22, p=.43\right)$.

The set of multigroup confirmatory factor models with ascending restrictiveness used to test measurement invariance for the two trait factors across Germany and Spain is presented in Table 2. The fourth model fit significantly worse compared with the third model; thus, strict measurement invariance did not apply. Scalar invariance, however, was not rejected, indicating strong measurement invariance across groups and permitting meaningful comparisons in the context of the present research question (cf. Meredith and Teresi 2006).
Descriptive statistics for instrumentality, expressiveness, and alcohol use across Germany and Spain are given in Table 3. The MANOVA yielded significant overall effects of nationality, $F(3,147)=5.31, p<.01$, and of Nationality $\times$ Time condition, $F(3,147)=7.55, p<.001$. Results of the single ANOVAs revealed no significant mean differences between the countries on instrumentality, $F(1,149)=.06$, $p=.81$, or expressiveness, $F(1,149)=2.76, p=.10$, but revealed significant differences for the number of days of daytime or nighttime alcohol use, $F(1,149)=9.52, p<.01$, which was greater for the Spanish sample $(M=2.0, S D=$ 1.6) than for the German sample $(M=1.5, S D=1.3)$. With regard to the interaction, the single ANOVAs yielded no significant differences on instrumentality, $F(1,149)=1.74$, $p=.19$, or expressiveness, $F(1,149)=.00, p=1.0$, which implies comparability of participants in the time conditions with regard to nationality and the gender-related traits. The interaction was significant in the single ANOVA for alcohol use, $F(1,149)=21.27, p<.001$. Subsequent $t$ tests between the two countries revealed no significant differences for nighttime alcohol use, $t(69)=1.46, p=.15$; however, daytime alcohol use was more frequent in the Spanish than in the German sample, $t(50)=-4.16, p<.001$.

\section{Research Question 1: Predictors of Daytime Alcohol Use}

Daytime alcohol use was expected to be more frequent in the Spanish sample, with higher scores on instrumentality, and with lower scores on expressiveness; the interaction of both trait scales should be related to daytime alcohol use; the predictions for instrumentality, expressiveness, and their interaction were expected to differ in strength depending on cultural differences. Hence, nationality, the latent factors of instrumentality and expressiveness, their interaction, and their interactions with nationality, were entered in a poisson regression analysis to predict the frequency of daytime alcohol use. At this time, only two-way interactions including latent variables are supported in Mplus. Thus,

Table 2 Model fit indices and Chi-square difference tests for the series of models with ascending restrictiveness in the course of testing crossnational measurement invariance for the trait factors instrumentality and expressiveness

\begin{tabular}{|c|c|c|c|c|c|c|c|c|}
\hline Model & $\mathrm{df}$ & $\chi^{2}$ & CFI & TLI & RMSEA & SRMR & $\Delta \mathrm{df}$ & $\Delta \chi^{2}$ \\
\hline 1. Configural invariance & 58 & 69.57 & .97 & .95 & .05 & .09 & & \\
\hline 2. Metric invariance & 66 & 71.98 & .98 & .98 & .03 & .09 & & \\
\hline 1 versus 2 & & & & & & & 8 & 4.05 \\
\hline 3. Scalar invariance & 74 & 79.08 & .99 & .98 & .03 & .09 & & \\
\hline 2 versus 3 & & & & & & & 8 & 7.03 \\
\hline 4. Residual variance invariance & 84 & $115.58^{*}$ & .91 & .90 & .07 & .16 & & \\
\hline 3 versus 4 & & & & & & & 10 & $40.56^{* * *}$ \\
\hline
\end{tabular}

Confirmatory factor analyses using robust maximum likelihood estimation. Less than $1 \%$ missing values, treated with FIML.

$* p<.05 . * * * p<.001$. 
Table 3 Descriptive statistics for the study variables across countries

\begin{tabular}{|c|c|c|c|c|c|c|}
\hline & \multicolumn{3}{|c|}{ Germany } & \multicolumn{3}{|c|}{ Spain } \\
\hline & $M$ & $S D$ & Range & $M$ & $S D$ & Range \\
\hline Instrumentality $^{\mathrm{a}}$ & 5.1 & .9 & $2.6-7.0$ & 5.0 & .9 & $1.6-6.8$ \\
\hline Expressiveness $^{\mathrm{a}}$ & 4.9 & 1.1 & $1.8-7.0$ & 5.1 & .9 & $2.6-7.0$ \\
\hline Daytime alcohol use ${ }^{b}$ & $1.1^{\mathrm{d}}$ & 1.2 & $0-4$ & $2.9^{\mathrm{d}}$ & 2.0 & $0-7$ \\
\hline Nighttime alcohol use ${ }^{c}$ & 1.8 & 1.4 & $0-5$ & 1.5 & .8 & $0-3$ \\
\hline
\end{tabular}

Less than $1 \%$ missing values, treated with the EM algorithm in NORM.

${ }^{a}$ possible values from 1 to 7 .

${ }^{\mathrm{b}}$ Number of days in which any alcohol was consumed before 6 p.m. within a typical week.

${ }^{c}$ Number of evenings in which several glasses of alcohol were consumed within a typical week.

${ }^{\mathrm{d}}$ Significantly different means at $p<.001$ (two-tailed).

we explored the three-way interaction of instrumentality, expressiveness, and nationality in analyses separately for each country, which yielded no significant Instrumentality $x$ Expressiveness interaction.

With regard to daytime alcohol use, two predictors were significant (see Table 4a). The incidence rate of days of alcohol use for German men was only .34 times the number of days of alcohol use for Spanish men. Expressiveness was associated with less frequent daytime alcohol use: A 1-unit increase in expressiveness was related to .74 times as many days of alcohol use.

\section{Research Question 2: Predictors of Nighttime Alcohol Use}

Based on available previous research, it was not clear whether nationality would be related to the frequency of nighttime alcohol use. Nighttime alcohol use was expected to be more frequent with higher scores on instrumentality and with lower scores on expressiveness; the interaction of both trait scales should be related to nighttime alcohol use; the predictions for instrumentality, expressiveness, and their interaction were expected to differ in strength depending on cultural differences. The poisson regression analysis predicting nighttime alcohol use was conducted analogous to that of daytime alcohol use. Again, the exploration of the three-way interaction of instrumentality, expressiveness, and nationality in regression analyses conducted separately for each country yielded no significant Instrumentality $\times$ Expressiveness interaction.

With regard to nighttime alcohol use, three predictors were significant (see Table 4b). Instrumentality had an increasing effect on frequency of nighttime alcohol use, which was qualified by a disordinal interaction with nationality. Furthermore, expressiveness affected nighttime alcohol use depending on nationality. Separate poisson regression analyses for each country indicated that instrumentality was positively related to nighttime alcohol use for Spanish men $(B=.26, S E=.10, p<.01, \mathrm{IRR}=1.30)$, but not
Table 4 Poisson regression analyses predicting frequency of alcohol use

Less than $1 \%$ missing values, treated with FIML. Incidence Rate Ratios (IRR) derived from exponentiated regression coefficients.

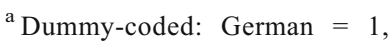
Spanish $=0$.

${ }^{\mathrm{b}}$ Standardized latent variable with mean fixed at zero and variance set to one.

${ }^{*} p<.05 .{ }^{* *} p<.01 .{ }^{* * *} p<.001$.

\begin{tabular}{lllll}
\hline & $B$ & $S E$ & $95 \%$ CI & IRR \\
\hline a. Daytime alcohol use & & & & \\
Nationality $^{\mathrm{a}}$ & $-1.07^{* * *}$ & .28 & -1.61 to -.53 & .34 \\
Instrumentality $^{\mathrm{b}}$ & .00 & .21 & -.41 to .42 & 1.00 \\
Expressiveness $^{\mathrm{b}}$ & $-.30^{*}$ & .15 & -.60 to -.02 & .74 \\
Instrumentality $\times$ Expressiveness & .18 & .10 & -.03 to .38 & 1.20 \\
Nationality $\times$ Instrumentality & .31 & .36 & -.39 to 1.00 & 1.40 \\
Nationality $\times$ Expressiveness & .01 & .25 & -.49 to .51 & 1.01 \\
& & & & \\
b. Nighttime alcohol use & .16 & .15 & -.14 to .46 & 1.17 \\
Nationality & & .10 & .10 to .49 & 1.34 \\
Instrumentality $^{\mathrm{b}}$ & $.29^{* *}$ & .13 & -.10 to .40 & 1.16 \\
Expressiveness $^{\mathrm{b}}$ & .15 & .08 & -.29 to .05 & .89 \\
Instrumentality $\times$ Expressiveness $^{\text {Nationality } \times \text { Instrumentality }}$ & -.12 & .14 & -.71 to -.16 & .64 \\
Nationality $\times$ Expressiveness & $-.44^{* *}$ & .16 & -.76 to -.14 & .64 \\
\hline
\end{tabular}


for German men $(B=-.13, S E=.10, p=.20, \quad \mathrm{IRR}=0.88)$. Expressiveness had a significant decreasing effect on the frequency of nighttime alcohol use for German men $(B=-.30, S E=.10, p<.01, \mathrm{IRR}=0.74)$, but not for Spanish men $(B=.06, S E=.12, p=.65$, IRR=1.06).

\section{Discussion}

Since constructions of gender and drinking habits differ cross-culturally, the present study aimed to extend previous research on gender roles and alcohol use to men from Germany and Spain. Gender roles were operationalized using gender-related personality traits, which were demonstrated to comparably measure instrumentality and expressiveness across both nations.

As expected, daytime alcohol use was significantly more frequent in Spanish than in German adults. Both cultural samples did not differ in their frequency of heightened alcohol use in the evenings or in gender-related personality traits on average. Instrumentality and expressiveness were, nevertheless, differentially predictive of nighttime alcohol use, which can still be interpreted as a masculine activitysince predictions for each country were in line with expectancies according to traditional gender-role stereotypes. Drinking several glasses of alcohol in the evenings was more frequent in Spanish men, who were high on instrumentality, and less frequent in German men, who were high on expressiveness. The measure used assesses positively valued attributes that cover broad genderstereotyped personality dimensions. Some previous studies had detected that only the narrower, more extreme trait of unmitigated agency (but not of agency) was positively related to health-risk behaviors such as substance use (Danoff-Burg et al. 2006), and use of alcohol, tranquilizers, and sedatives (Snell et al. 1987). Doubt may have been cast on the relation between gender-related traits and alcohol use due to previous studies that found no such evidence for agency in men (McCreary et al. 1999), or for instrumentality in adolescents (Huselid and Cooper 1992). These studies simultaneously tested multiple (correlated) measures of gender roles, raising questions about possible multicollinearity in the data that prevented single paths from reaching significance. By contrast, our results-at least with regard to Spanish men - are in line with existing research on gender roles and men's health practices (Landrine et al. 1988; Mahalik et al. 2006, 2007b), and suggest that men who internalize traditionally masculine attributes subscribe to stereotypically masculine behaviors like alcohol consumption.

Little was known to date about the role of feminine qualities in the context of men's alcohol use (Snell et al. 1987). The protective function of expressiveness, which was associated with less frequent daytime alcohol use in men independent of nationality and to less frequent nighttime alcohol use in German men, is a striking finding of our study. Men who were more able to identify themselves with traditionally feminine attributes subscribed less to the stereotypically masculine behavior of alcohol consumption. What mediates the influence of such a broad personality disposition as expressiveness on behavior is still left to speculation, though. One possible mechanism is that men with higher expressiveness are more sensitive to their bodies and to somatic symptoms compared with men lower in expressiveness, and thus, may constrain their drinking to a naturally perceived, less hazardous limit. High expressiveness in men may also serve as a buffer against social pressure to act in accordance with behavioral norms that are traditionally viewed as male-appropriate. This has also been suggested by researchers who found that androgynous individuals, who are high on instrumentality and expressiveness, drink and smoke less than masculine individuals who are high on instrumentality but low on expressiveness (Evans et al. 1990; Shifren et al. 1993). Finally, it might be their higher sensitivity to the sentiments of others that leads men high on expressiveness to curb their drinking. They may consider, for example, that others may express disgust when observing heavy drinking, whereas those with lower expressiveness may ignore such feelings of others. Future research should go beyond the gender-related trait approach and focus on those mediating processes. Future studies may also show whether reduced alcohol consumption explains the relation between expressiveness and decreased risk of death from coronary heart disease among men as was found by Hunt and colleagues (2007).

Our findings point to the importance of (changing) gender roles. Societal changes comprising changes in traditional gender roles have taken place, involving a break-up in the male gender role, which may be reflected in an enlargement of men's self-concepts. Legal amendments and the subsequent rapidly increasing percentage of men taking their legally granted parental leave in Germany (Pfahl and Reuyß 2009), for example, may allow German men to behave in a less gender-stereotypic fashion. It may thus be more socially accepted for German men to act upon their communal and nurturing traits than for Spanish men, where comparable legal regulations are not at hand. This might explain findings regarding nighttime drinking in German as opposed to Spanish men, who are on average similarly expressive, but are exposed to a more restrictive environment because they experience more segregation between gender roles (Eurostat 2006; López-Sáez et al. 2008).

Findings on masculinity and health-related behaviors mainly based on US samples appear to be partly generalizable to men from other countries such as Australia 
(Brown and Bond 2008; Mahalik et al. 2007b) and Kenya (Mahalik et al. 2006). The present study provides additional evidence that the relations between gender roles and healthrelated behaviors may be principally generalizable to men from other countries with similar gender stereotypes. Research suggests that there is a certain overlap in gender stereotypes in most countries. Masculine ideologies are characterized, for example, by risk taking, strength, and avoidance of femininity in most of the world (Gilmore 1990b; Williams and Best 1990). Furthermore, scholars from different disciplines share a constructivist view on gender (Deaux and LaFrance 1998; Gilmore 1990b) as resulting from the distribution of social roles (Eagly et al. 2000), performance of health-related behaviors (Courtenay 2000b), or drinking alcohol as a masculine activity (Lemle and Mishkind 1989; Waldron 1997). The connection between drinking and masculine attributes (e.g., strong personality, willingness to take risks), and infrequent drinking and feminine attributes (e.g., tender, compassionate) in German and Spanish males is, therefore, consistent with the pervasiveness of gender stereotypes.

\section{Strengths and Limitations}

As an important requirement to warrant valid conclusions in cross-cultural research, the testing of measurement invariance is requested (Steenkamp and Baumgartner 1998) but seldom reported. Cross-national measurement invariance was empirically demonstrated in this study. Nevertheless, the findings must be qualified by the following limitations.

First of all, results are limited in their generalizability by the fact that the samples consisted of university students. We do not assume that the links between gender-related personality traits and alcohol use are restricted to these particular men. Hence, the findings need to be replicated in future studies with different samples and age groups. Second, the study design was cross-sectional. Given the correlational nature of the findings, inferences about causal relationships between the predictors and men's alcohol use are not warranted. Internalized gender-related traits result from an adoption of gender-typed norms as personal standards for judging one's own behavior; once established in adolescence, it appears that the gender-related selfconcept remains relatively stable (Eagly et al. 2000; Hannover 2000). It is thus likely that instrumental and expressive attributes, overall, precede alcohol use. Third, we did not fully investigate "masculinity" and "femininity," but examined gender-stereotyped personality attributes as facets of the superordinate constructs. The traits may be less differentially desirable for a man or a woman by now, but rather provide indices of the degree to which individuals describe themselves as having instrumental/agentic and expressive/communal attributes (cf. Hoffman and Borders 2001). Nevertheless, since the BSRI was developed, it has been shown that although the magnitude of differential desirability has decreased, the differences in desirability of the attributes for a man or a woman by and large still exist (Holt and Ellis 1998).

Although future research is needed to address the limitations of this study, we believe the findings help to explain why some men have higher rates of alcohol use than others. Our findings on men from two countries with differences in gender equality and drinking cultures add support to the assumption that social constructions of gender are important for health-risk behaviors. Specifically, they present some empirical support for the hypothesis that alcohol use is associated with the internalization of traditionally masculine attributes into the self-concept and with the rejection of attributes linked with the traditional female gender role, which rather has a protective effect against frequent alcohol use.

Acknowledgments The authors wish to thank Rocio GarciaRetamero and Sarah Diana Haug for their help with translating the questionnaires and Jane Thompson for carefully checking the language of the manuscript.

\section{References}

Bem, S. L. (1974). The measurement of psychological androgyny. Journal of Consulting and Clinical Psychology, 42, 155-162. doi: $10.1037 / \mathrm{h} 0036215$.

Bem, S. L. (1977). On the utility of alternative procedures for assessing psychological androgyny. Journal of Consulting and Clinical Psychology, 45, 196-205.

Bem, S. L. (1981). Bem sex role inventory professional manual. Palo Alto: Consulting Psychologists Press.

Bloomfield, K., Stockwell, T., Gmel, G., \& Rehn, N. (2003). International comparisons of alcohol consumption. Alcohol Research \& Health, 27, 95-109.

British Medical Association. (1995). Alcohol: Guidelines on sensible drinking. London: British Medical Association.

Brown, L. J., \& Bond, M. J. (2008). An examination of the influences on health-protective behaviors among Australian men. International Journal of Men's Health, 7, 274-287. doi:10.3149/ jmh.0703.274.

Bundesministerium der Justiz. (2008). Jugendschutzgesetz (JuSchG) [Law for the protection of the youth]. Retrieved from http:// bundesrecht.juris.de/juschg/index.html.

Cohen, J., Cohen, P., West, S. G., \& Aiken, L. S. (2003). Applied multiple regression/correlation analysis for the behavioral sciences (3rd ed.). Mahwah: Lawrence Erlbaum Associates.

Corrao, G., Bagnardi, V., Zambon, A., \& La Vecchia, C. (2004). A meta-analysis of alcohol consumption and the risk of 15 diseases. Preventive Medicine, 38, 613-619. doi:10.1016/j. ypmed.2003.11.027.

Courtenay, W. H. (2000a). Constructions of masculinity and their influence on men's well-being: A theory of gender and health. Social Science \& Medicine, 50, 1385-1401. doi:10.1016/S02779536(99)00390-1. 
Courtenay, W. H. (2000b). Engendering health: A social constructionist examination of men's health beliefs and behaviors. Psychology of Men \& Masculinity, 1, 4-15. doi:10.1037/15249220.1.1.4.

Danoff-Burg, S., Mosher, C. E., \& Grant, C. A. (2006). Relations of agentic and communal personality traits to health behavior and substance use among college students. Personality and Individual Differences, 40, 353-363. doi:10.1016/j.paid.2005.05.020.

Deaux, K., \& LaFrance, M. (1998). Gender. In D. T. Gilbert, S. T. Fiske, \& G. Lindzey (Eds.), The handbook of social psychology, vol. 1 (4th ed., pp. 788-827). Boston: McGraw-Hill.

Eagly, A. H., Wood, W., \& Diekman, A. B. (2000). Social role theory of sex differences and similarities: A current appraisal. In T. Eckes \& H. M. Trautner (Eds.), The developmental social psychology of gender (pp. 123-174). Mahwah: Lawrence Erlbaum Associates Publishers.

Eurostat. (2006). A statistical view of the life of women and men in the EU25. Retrieved from http://ec.europa.eu/justice_home/ news/information_dossiers/international_womens_day_06/ statistics_men_women_en_06.pdf.

Evans, R. I., Turner, S. H., Ghee, K. L., \& Getz, J. G. (1990). Is androgynous sex role related to cigarette smoking in adolescents? Journal of Applied Social Psychology, 20, 494-505. doi:10.1111/ j.1559-1816.1990.tb00424.x.

Garcia-Retamero, R., \& Lopez-Zafra, E. (2006). Prejudice against women in male-congenial environments: Perceptions of gender role congruity in leadership. Sex Roles, 55, 51-61. doi:10.1007/ s11199-006-9068-1.

Gilmore, D. D. (1990a). Commodity, comity, and community: Male exchange in rural Andalucia. Ethnology, 30, 17-30.

Gilmore, D. D. (1990b). Manhood in the making: Cultural concepts of masculinity. New Haven: Yale University Press.

Gmel, G., Rehm, J., \& Kuntsche, E. (2003). Binge drinking in Europe: Definitions, epidemiology, and consequences. Sucht: Zeitschrift fuer Wissenschaft und Praxis, 49, 105-116.

Graham, J. W. (2009). Missing data analysis: Making it work in the real world. Annual Review of Psychology, 60, 549-576. doi:10.1146/annurev.psych.58.110405.085530.

Hannover, B. (2000). Development of the self in gendered contexts. In T. Eckes \& H. M. Trautner (Eds.), The developmental social psychology of gender (pp. 177-206). Mahwah: Lawrence Erlbaum Associates Publishers.

Helfferich, C. (1997). "Männlicher" Rauschgewinn und "weiblicher" Krankheitsgewinn? Geschlechtsgebundene Funktionalität von Problemverhalten und die Entwicklung geschlechtsbezogener Präventionsansätze ['Male' benefits from drunkenness, 'female' benefits from illness? Genderspecific functionality of deviant behavior and the development of genderspecific prevention programs]. Zeitschrift für Sozialisationsforschung und Erziehungssoziologie, 17, 148-161.

Hoffman, R. M., \& Borders, L. D. (2001). Twenty-five years after the Bem sex-role inventory: A reassessment and new issues regarding classification variability. Measurement and Evaluation in Counseling and Development, 34, 39-55.

Holt, C. L., \& Ellis, J. B. (1998). Assessing the current validity of the Bem sex-role inventory. Sex Roles, 39, 929-941. doi:10.1023/ a:1018836923919.

Hunt, K., Lewars, H., Emslie, C., \& Batty, G. D. (2007). Decreased risk of death from coronary heart disease amongst men with higher 'femininity' scores: A general population cohort study. International Journal of Epidemiology, 36, 612-620. doi:10.1093/ije/dym002.

Hupkens, C. L., Knibbe, R. A., \& Drop, M. J. (1993). Alcohol consumption in the European community: Uniformity and diversity in drinking patterns. Addiction, 88, 1391-1404. doi:10.1111/j.1360-0443.1993.tb02026.x.
Huselid, R. F., \& Cooper, M. L. (1992). Gender roles as mediators of sex differences in adolescent alcohol use and abuse. Journal of Health and Social Behavior, 33, 348-362. doi:10.2307/2137313.

Kuntsche, E., Rehm, J., \& Gmel, G. (2004). Characteristics of binge drinkers in Europe. Social Science \& Medicine, 59, 113-127. doi:10.1016/j.socscimed.2003.10.009.

Landrine, H., Bardwell, S., \& Dean, T. (1988). Gender expectations for alcohol use: A study of the significance of the masculine role. Sex Roles, 19, 703-712. doi:10.1007/bf00288986.

Leifman, H. (2002). A comparative analysis of drinking patterns in six EU countries in the year 2000. Contemporary Drug Problems, 29, 501-548.

Lemle, R., \& Mishkind, M. E. (1989). Alcohol and masculinity. Journal of Substance Abuse Treatment, 6, 213-222. doi:10.1016/ 0740-5472(89)90045-7.

Little, T. D., Slegers, D. W., \& Card, N. A. (2006). A non-arbitrary method of identifying and scaling latent variables in SEM and MACS models. Structural Equation Modeling, 13, 59-72. doi:10.1207/s15328007sem1301_3.

Lopez-Claros, A., \& Zahidi, S. (2005). Women's empowerment: Measuring the global gender gap. Geneva: World Economic Forum.

López-Sáez, M., Morales, J. F., \& Lisbona, A. (2008). Evolution of gender stereotypes in Spain: Traits and roles. The Spanish Journal of Psychology, 11, 609-617.

MacCallum, R. C., Zhang, S., Preacher, K. J., \& Rucker, D. D. (2002). On the practice of dichotomization of quantitative variables. Psychological Methods, 7, 19-40. doi:10.1037/1082989x.7.1.19.

Mahalik, J. R., Locke, B. D., Ludlow, L. H., Diemer, M. A., Scott, R. P. J., Gottfried, M., et al. (2003). Development of the conformity to masculine norms inventory. Psychology of Men \& Masculinity, 4, 3-25. doi:10.1037/1524-9220.4.1.3.

Mahalik, J. R., Lagan, H. D., \& Morrison, J. A. (2006). Health behaviors and masculinity in Kenyan and U.S. male college students. Psychology of Men \& Masculinity, 7, 191-202. doi:10.1037/1524-9220.7.4.191.

Mahalik, J. R., Burns, S. M., \& Syzdek, M. (2007a). Masculinity and perceived normative health behaviors as predictors of men's health behaviors. Social Science \& Medicine, 64, 2201-2209. doi:10.1016/j.socscimed.2007.02.035.

Mahalik, J. R., Levi-Minzi, M., \& Walker, G. (2007b). Masculinity and health behaviors in Australian men. Psychology of Men \& Masculinity, 8, 240-249. doi:10.1037/1524-9220.8.4.240.

Mäkelä, P., Gmel, G., Grittner, U., Kuendig, H., Kuntsche, S., Bloomfield, K., et al. (2006). Drinking patterns and their gender differences in Europe. Alcohol and Alcoholism, 41, 8-18. doi:10.1093/alcalc/ag1071.

McCreary, D. R., Newcomb, M. D., \& Sadava, S. W. (1999). The male role, alcohol use, and alcohol problems: A structural modeling examination in adult women and men. Journal of Counseling Psychology, 46, 109-124. doi:10.1037/00220167.46.1.109.

Meredith, W., \& Teresi, J. A. (2006). An essay on measurement and factorial invariance. Medical Care, 44, S69-S77. doi:10.1097/01. mlr.0000245438.73837.89.

Ministerio de Sanidad y Consumo. (2008). Ganar salud con la juventud [Obtaining young people's health]. Retrieved from http://www.msps.es/ciudadanos/proteccionSalud/adolescencia/ docs/jovenes_2008.pdf.

Muthén, L. K., \& Muthén, B. O. (1998-2007). Mplus user's guide (5th ed.). Los Angeles: Muthén \& Muthén.

Muthén, L. K., \& Muthén, B. O. (2008). Mplus version 5.2 [Computer Software].

Nolen-Hoeksema, S., \& Hilt, L. (2006). Possible contributors to the gender differences in alcohol use and problems. The Journal of 
General Psychology, 133, 357-374. doi:10.3200/GENP.133.4.357374.

Peralta, R. L. (2007). College alcohol use and the embodiment of hegemonic masculinity among European American men. Sex Roles, 56, 741-756. doi:10.1007/s11199-007-9233-1.

Perkins, H. W. (2002). Surveying the damage: A review of research on consequences of alcohol misuse in college populations. Journal of Studies on Alcohol, 91-100.

Pfahl, S., \& Reuyß, S. (2009). Das neue Elterngeld-Erfahrungen und betriebliche Nutzungsbedingungen von Vätern [The new family allowance-Experiences and fathers working conditions of use] (Gender, Familie und Beruf ed. Vol. 239). Düsseldorf: HansBöckler-Stiftung.

Robert Koch-Institut (2003). Bundes-Gesundheitssurvey: Alkohol [Federal health survey: Alcohol]. Berlin: Robert Koch-Institut.

Rodríguez-Martos Dauer, A., Gual Solé, A., \& Llopis Llácer, J. J. (1999). La "unidad de bebida estándar" como registro simplificado del consumo de bebidas alcohólicas y su determinación en España [The "standard drinking unit" as a simplified recording system of alcohol consumption and its measurement in Spain]. Medicina Clínica, 112, 446-450.

Room, R., \& Mäkelä, K. (2000). Typologies of the cultural position of drinking. Journal of Studies on Alcohol, 61, 475-483.

Schafer, J. L. (1999). NORM: Multiple imputation of incomplete multivariate data under a normal model, version 2.03 for Windows 95/98/NT [Computer Software].

Schneider-Düker, M., \& Kohler, A. (1988). Die Erfassung von Geschlechtsrollen-Ergebnisse zur deutschen Neukonstruktion des Bem Sex-Role-Inventory [The Assessment of gender rolesResults of the german revised construction of the Bem Sex-RoleInventory]. Diagnostica, 34, 256-270.

Shifren, K., Bauserman, R., \& Carter, D. B. (1993). Gender role orientation and physical health: A study among young adults. Sex Roles, 29, 421-432. doi:10.1007/bf00289433.

Snell, W. E., Belk, S. S., \& Hawkins, R. C. (1987). Alcohol and drug use in stressful times: The influence of the masculine role and sex-related personality attributes. Sex Roles, 16, 359-373. doi: $10.1007 / \mathrm{bf} 00289548$.

Spence, J. T., \& Helmreich, R. L. (1978). Masculinity and femininity: Their psychological dimensions, correlates and antecedents. Austin: University of Texas Press.

Steenkamp, J.-B. E. M., \& Baumgartner, H. (1998). Assessing measurement invariance in cross-national consumer research.
Journal of Consumer Research, 25, 78-90. doi:10.1086/ 209528.

Steinmetz, H., Schmidt, P., Tina-Booh, A., Wieczorek, S., \& Schwartz, S. H. (2009). Testing measurement invariance using multigroup CFA: Differences between educational groups in human values measurement. Quality \& Quantity, 43, 599-616. doi:10.1007/s11135-007-9143-x.

Stöver, H. (2007). Mann, Rausch, Sucht: Konstruktionen und Krisen von Männlichkeiten [Man, intoxication, addiction: Constructions and crises of masculinities]. Suchttherapie, 8, 89-94.

Tager, D., \& Good, G. E. (2005). Italian and American masculinities: A comparison of masculine gender role norms. Psychology of Men \& Masculinity, 6, 264-274. doi:10.1037/1524-9220.6.4.264.

United Nations Development Programme. (2003). Human development report: Millennium development goals: A compact among nations to end human poverty. New York: Oxford University Press.

Van Gundy, K., Schieman, S., Kelley, M. S., \& Rebellon, C. J. (2005). Gender role orientations and alcohol use among Moscow and Toronto adults. Social Science \& Medicine, 61, 2317-2330. doi:10.1016/j.socscimed.2005.07.033.

Vandenberg, R. J., \& Lance, C. E. (2000). A review and synthesis of the measurement invariance literature: Suggestions, practices, and recommendations for organizational research. Organizational Research Methods, 3, 4-69. doi:10.1177/109442810031002.

Waldron, I. (1988). Gender and health-related behavior. In D. S. Gochman (Ed.), Health behavior: Emerging research perspectives (pp. 193-208). New York: Plenum Press.

Waldron, I. (1997). Changing gender roles and gender differences in health behavior. In D. S. Gochman (Ed.), Handbook of health behavior research 1: Personal and social determinants (pp. 303328). New York: Plenum Press.

Williams, J. E., \& Best, D. L. (1990). Measuring sex stereotypes: A multination study (rev. ed.). Thousand Oaks: Sage Publications, Inc.

Wilsnack, R. W., Vogeltanz, N. D., Wilsnack, S. C., \& Harris, T. R. (2000). Gender differences in alcohol consumption and adverse drinking consequences: Cross-cultural patterns. Addiction, 95, 251-265. doi:10.1080/09652140031928.

Wilsnack, R. W., Wilsnack, S. C., Kristjanson, A. F., Vogeltanz-Holm, N. D., \& Gmel, G. (2009). Gender and alcohol consumption: Patterns from the multinational GENACIS project. Addiction, 104, 1487-1500. doi:10.1111/j.1360-0443.2009.02696.x. 
Copyright of Sex Roles is the property of Springer Science \& Business Media B.V. and its content may not be copied or emailed to multiple sites or posted to a listserv without the copyright holder's express written permission. However, users may print, download, or email articles for individual use. 